\title{
E-LEARNING BASED DISTANCE EDUCATION PROGRAMME ON REMOTE SENSING AND GEOINFORMATION SCIENCE - AN INITIATIVE OF IIRS
}

\author{
Harish Karnatak *, P.L.N. Raju, Y.V.N. Krishna Murthy, S.K. Srivastav and Prasun Kumar Gupta \\ Indian Institute of Remote Sensing, Indian Space Research Organization, Department of Space, Govt. of India, Dehradun, "harish@iirs.gov.in
}

\author{
Commission VIII, WG VI/4
}

KEYWORDS: e-learning, distance education, tele-education, Internet, Remote Sensing, GIS and GNSS

\begin{abstract}
:
IIRS has initiated its interactive distance education based capacity building under IIRS outreach programme in year 2007 where more than 15000+ students were trained in the field of geospatial technology using Satellite based interactive terminals and internet based learning using A-View software. During last decade the utilization of Internet technology by different user groups in the society is emerged as a technological revaluation which has directly affect the life of human being. The Internet is used extensively in India for various purposes right from entrainment to critical decision making in government machinery. The role of internet technology is very important for capacity building in any discipline which can satisfy the needs of maximum users in minimum time. Further to enhance the outreach of geospatial science and technology, IIRS has initiated e-learning based certificate courses of different durations. The contents for e-learning based capacity building programme are developed for various target user groups including mid-career professionals, researchers, academia, fresh graduates, and user department professionals from different States and Central Government ministries. The official website of IIRS e-learning is hosted at http://elearning.iirs.gov.in. The contents of IIRS e-learning programme are flexible for anytime, anywhere learning keeping in mind the demands of geographically dispersed audience and their requirements. The program is comprehensive with variety of online delivery modes with interactive, easy to learn and having a proper blend of concepts and practical to elicit students' full potential. The course content of this programme includes Image Statistics, Basics of Remote Sensing, Photogrammetry and Cartography, Digital Image Processing, Geographical Information System, Global Positioning System, Customization of Geospatial tools and Applications of Geospatial Technologies. The syllabus of the courses is as per latest developments and trends in geo-spatial science and technologies with specific focus on Indian case studies for geo-spatial applications. The learning is made available through interactive 2D and 3D animations, audio, video for practical demonstrations, software operations with free data applications. The learning methods are implemented to make it more interactive and learner centric application with practical examples of real world problems.
\end{abstract}

\section{INTRODUCTION}

During last decade the utilization of Internet technology by different user groups in the society is emerged as a technological revaluation which has directly affect the life of human being (Karnatak et al, 2012). The Internet is used extensively in India for various purposes right from entrainment to critical decision making in government machinery. The role of internet technology is very important for capacity building in any discipline which can satisfy the needs of maximum users in minimum time. The successful implementations of internet based e-learning methods are already demonstrated for many areas in worldwide (http://www.creativity-portal.com, www.wannalearn.com, http://www.howstuffworks.com/ etc.). However it is very limited in India especially in the fields of space science and geospatial technologies. Remote Sensing and geo-information science have become key technology tools for the collection, storage and analysis of spatially referenced data for resource planning and decision making (Karnatak et al, 2007). Today it is the backbone to many decision-making systems and location-based services emerging in the new information economy. Planners and decision makers' that utilize these geo-spatial technologies for variety of applications in agriculture, forestry, mining, market research, environmental analysis as well as the social, utility services and disaster management.

Indian Institute of Remote Sensing (IIRS), ISRO Dehradun India is actively involved in training capacity building in the area of remote sensing and geo-spatial technologies through short and long term courses. Further to enhance the outreach of geospatial science and technology IIRS has initiated e-learning based certificate course on Remote Sensing and Geoinformation science of different durations. The contents for elearning based capacity building programme are developed for various target user groups including mid-career professionals, researchers, academia, fresh graduates, and user department professionals from different States and Central Government ministries.

The contents of IIRS e-learning programme are flexible for anytime, anywhere learning keeping in mind and met the demands of geographically dispersed audience and their requirements. The program is comprehensive with variety of online delivery modes with interactive, easy to learn and having a proper blend of concepts and practical to elicit students' full potential. The course content of this programme includes Image Statistics, Basics of Remote Sensing, Photogrammetry and Cartography, Digital Image Processing, Geographical Information System, Global Positioning System, Customization of Geospatial tools and Applications of Geospatial Technologies. The syllabus of the courses is as per latest developments and trends in geo-spatial science and technologies with specific focus on Indian case studies for geo-spatial applications. The learning is made available through interactive 2D and 3D animations, audio, video for practical demonstrations, software operations with free data applications. The learning methods are implemented to make it more interactive and learner centric application with practical examples of real world problems.

In the development of IIRS e-learning web portal the open source software architecture is used to make it open and 
interoperable system. This e-learning programme is also accessible through National Knowledge Network (NKN) of Government of India to address the capacity building requirement of NKN knowledge Institution. This article presents the various technological issues related e-learning based capacity building and initiatives of IIRS in this domain.

\section{E-LEARNING BASED EDUCATION SYSTEM}

E-learning or electronics based learning is the use of electronic media with Information and communication technologies (ICT) in capacity building including training and education. Elearning includes numerous types of media that deliver text, audio, images, animation, and streaming video, and includes technology applications and processes such as audio or video tape, satellite TV, CD-ROM, and computer-based learning, as well as local intranet and web-based learning (Tavangarian et al, 2004). E-learning contents can be accessed by the students during live classrooms or in out of the classroom. It can be selfpaced, asynchronous learning or may be instructor-led, synchronous learning. E-learning is suited to distance learning and flexible learning, but it can also be used in conjunction with face-to-face teaching, in which case the term blended learning is commonly used (Wikipedia, accessed $12^{\text {th }}$ Nov. 2014). Elearning based learning methodologies are also known as, technology-enhanced learning (TEL), computer-based instruction (CBI), Computer-based training (CBT), computerassisted instruction or computer-aided instruction (CAI), internet-based training (IBT), flexible learning, web-based training (WBT), online education, virtual education, virtual learning environments (VLE), digital education, tele-education etc. The learning methodologies in different modes were presented by Nick Van Dam using education model of Charles Merril, 1960 (Mayer, 1960) as shown in Figure 1.

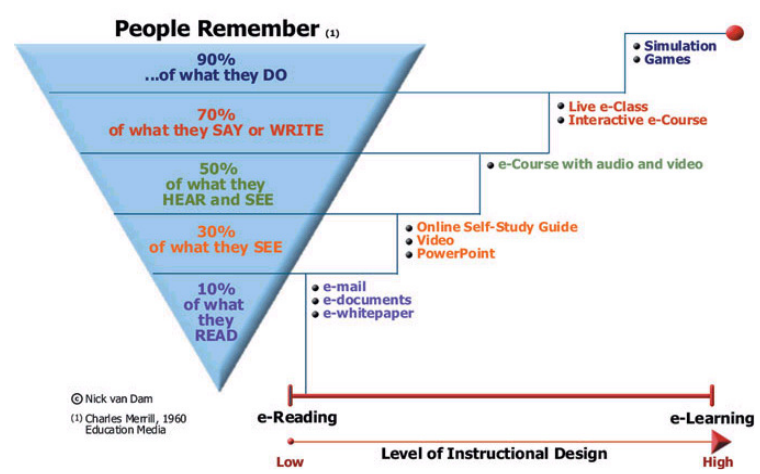

Figure 1- Online Learning Continuum

The levels of instructional design are very high in e-learning based system rather than e-reading. In learning methodology for online learners the most effective mode is learning through simulations and online gaming where the learner is involved in the activity. The virtualization of classroom through internet media is one of the emerging domain in e-learning environment. Here the term "Virtual" is used to describe a course that not taught in a classroom face-to-face but through a substitute mode that can conceptually be associated "virtually" with classroom teaching. In virtual classroom the student participates from remote places in live classrooms.

The e-learning based systems are typically depends on internet and multimedia technologies which are the basic enabler of online learning.
The extent to which e-learning assists or replaces other learning and teaching approaches is variable, ranging on a continuum from none to fully online distance learning (Bates, A. and Poole, G., 2003; OECD, 2005). Further the concept of elearning can be sub divided in to four major categories:

2.1 Synchronous e-learning: Synchronous learning occurs in real-time, with all participants interacting at the same time through some media like face-to-face discussions, live chat (audio, video and text), live lecture delivery, virtual classroom etc. The virtual classroom is one of the most popular technique which getting very popular among learners.

2.2 Asynchronous e-learning: asynchronous learning is selfmotivated and allows learner to engage in the exchange of ideas or information without the dependency of other participants or involvement of trainer at the same time. Asynchronous learning may use technologies such as email, blogs, wikis, and discussion boards, as well as web-supported textbooks, hypertext documents (HTML, XML etc.), audio, video lectures, and social networking using web 2.0 (Loutchkoet et al, 2002).

Asynchronous learning is very effective for the working professionals or the participants those are not able to participate in lectures or practical in pre-fix time slot. In asynchronous mode of online courses, the participant proceed at their own pace and convenience. Both the asynchronous and synchronous methods rely heavily on self-motivation, self-discipline, and the ability to communicate in writing effectively.

2.3 Linear learning: Linear learning or e-reading through Computer-Based Learning or Training (CBT) refers to selfpaced learning activities delivered on a computer or handheld device such as a tablet or smartphone. Zahm (2000) described computer-based training (CBT) as usually delivered via CDROM or as a Web download and that it is usually multimediabased training. Karon (2000) discussed the convenience factor of well-designed computer-based training by saying that any well-designed computer-based training- whether it's networked based or delivered via the Internet - is more convenient than traditional instructor-led training or seminars.

2.4 Collaborative learning: Computer-supported collaborative learning (CSCL) uses instructional methods designed to encourage or require students to work together on learning tasks. CSCL is similar in concept to the terminology, "e-learning 2.0" and "networked collaborative learning" (NCL) (Trentin G., 2010). The utilization of Web 2.0 technology for collaborative learning is very successful by using Blogs, wikis, discussion forum, social networking, live chat, etc.

\section{TECHNOLOGICAL STANDARDS FOR E- LEARNING}

The standards for contents creation and development of Learning Management System are important to achieve interoperability among learning objects in Internet environment. A learning management system (LMS) is software used for delivering, tracking and managing training and education. The first e-learning standards were developed by Aviation Industry CBT Committee (AICC) (www.aicc.org). AICC brings together trainers, courseware developers, software vendors, simulator designers and airframe manufacturers to develop standards, technology recommendations and analysis of best practices (www.courseavenue.com). The most popular AICC standards are AICC documents AGR-006 (File-based CMI Systems) and AGR-010 (Web-based CMI Systems). 
Another important e-learning object is Sharable Content Object Reference Model (SCORM) which integrates a set of related technical standards, specifications, and guidelines designed to meet requirements including accessibility, interoperability, durability, and reusability of content and systems. The elearning contents based on SCORM standard are delivered through SCORM compliant Learning Management System (LMS) like Moodle, Blackboard, A-tutor etc. SCORM is produced by Advance Distributed Learning (ADL), a research group sponsored by the United States Department of Defence. Since its establishment in 1997, ADL has worked with military and government agencies, industry, academia, and professional organizations world-wide to accomplish its mission and realize its vision that learning experiences must be accessible to all online and on demand (www.courseavenue.com). The SCORM version 1.1, 1.2 and 2004 are available for their implementation in LMS. The SCROM $3^{\text {rd }}(2005)$ and $4^{\text {th }}$ edition (2009) are most popular and widely used standards implemented in majority of LMS.

The Tin Can API is latest development in e-learning object standards. The first version of Tin Can API is published in April 2013 and had its name changed to "Experience API" (xAPI) and "Next Generation SCORM" (SCORM, 2014). The Tin Can API solves many of the problems inherent with older versions of SCORM (SCORM, 2014).

\section{IIRS INITIATIVES IN E-LEARNING}

\subsection{Development of Contents and LMS}

The e-reading based systems works on downloading the reading contents and read it offline while e-learning is a systematic learning system which guides the learners online with various learning methodologies implemented in LMS. IIRS has developed e-learning contents and LMS for different certificate courses in Remote Sensing and geo-spatial technology. The syllabus of the courses are as per latest developments and trends in geo-spatial science and technologies with specific focus on Indian case studies for geo-spatial applications. The learning is made available through interactive $2 \mathrm{D}$ and $3 \mathrm{D}$ animations, audio, video for practical demonstrations, software operations with free data applications. The learning methods are implemented to make it more interactive and learner centric application with practical examples of real world problems.

Table 1- Distribution of e-learning hours for available courses under IIRS e-learning programme.

\begin{tabular}{|l|c|c|}
\hline \multirow{2}{*}{ Subject } & \multicolumn{2}{|c|}{ e-learning hours } \\
\cline { 2 - 3 } & Theory & Practical \\
\hline Image Statistics & 3 & 2 \\
\hline Basic Remote Sensing & 19 & 3 \\
\hline $\begin{array}{l}\text { Photogrammetry and } \\
\text { Cartography }\end{array}$ & 12 & 2 \\
\hline Digital Image Processing & 14 & 7 \\
\hline $\begin{array}{l}\text { Geographical Information } \\
\text { System }\end{array}$ & 19 & 7 \\
\hline $\begin{array}{l}\text { Global Navigation Satellite } \\
\text { System }\end{array}$ & 4 & 2 \\
\hline $\begin{array}{l}\text { Customization of Geospatial } \\
\text { Tools }\end{array}$ & 3 & 5 \\
\hline $\begin{array}{l}\text { Applications of Geospatial } \\
\text { Technologies-Theory }\end{array}$ & 4 & - \\
\hline
\end{tabular}

The e-learning contents are created as interactive multimedia application and integrated with customized LMS based on
Moodle. The user registration and admission module is developed outside Moodle LMS for proper user management and linking the participants with IIRS EDUSAT programme. The adopted e-learning objet standard and other technical details are shown in Table 2.

Table 2- Technologies and standards

\begin{tabular}{|l|l|}
\hline Component & Technology/Standard \\
\hline Operating System & Linux \\
\hline Database Server & MySQl \\
\hline Application Development & $\begin{array}{l}\text { PHP, Javascript and HTML, } \\
\text { Flash }\end{array}$ \\
\hline LMS & Moodle \\
\hline Web Server & Apache \\
\hline Object standard & SCORM 2004, $4^{\text {th }}$ edition \\
\hline Online classes & Apache OpenMeeting \\
\hline URL & http://elearning.iirs.gov.in \\
\hline
\end{tabular}

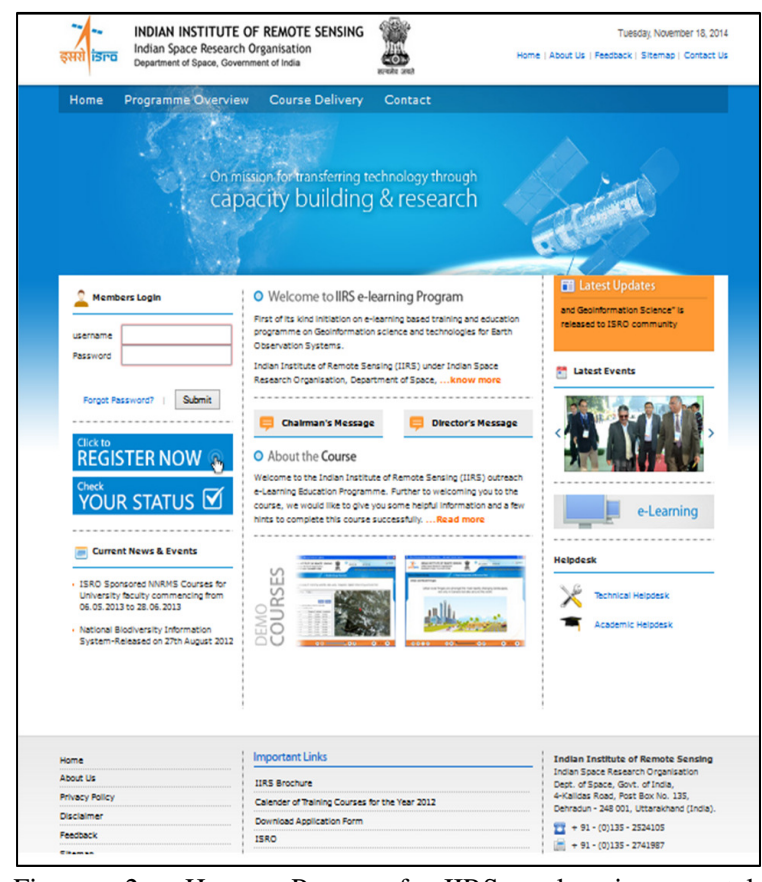

Figure 2- Home Page of IIRS e-learning portal (http://elearning.iirs.gov.in )

The hardware infrastructure is setup for 1000 concurrent learners with $100 \mathrm{Mbps}$ Internet connectivity from NKN. The open source software and data sets for practical exercises are also available to the participants. In future it is planned to give access to IIRS laboratory for practical exercises through private cloud.

\subsection{Structure of the Courses:}

The IIRS e-learning courses are flexible for anytime, anywhere learning keeping in mind the demands of geographically dispersed audience and their requirements. The program is comprehensive with variety of online delivery modes with interactive, easy to learn and having a proper blend of concepts and practical to elicit students' full potential. IIRS has initiated e-learning based distance learning programme with following major objectives:

a. To provide an opportunity for individuals to learn Remote Sensing and Geoinformation Science for the benefit of their professional career. This basic course in Remote Sensing and Geoinformation Science will allow graduates to build their knowledge and practical expertise in RS and GIS 
technologies with independent study and project experience at the certificate level.

b. To provide considerable flexibility allowing students to quickly gain the RS and GIS knowledge and qualification they need today, and to add to their credentials. Students develop a capacity for independent research, problem analysis and solution.

c. To empower students undertaking this course to develop their knowledge and understanding through formal coursework and a program of independent reading. It has a practical component and a project associated with it to develop learners' research, analytical and problem-solving skills.

Under IIRS e-learning programme following courses are available:

- Comprehensive certificate course on Remote Sensing and Geo-information Science- 4 Months duration.

\section{One month fundamental certificate courses on:}

- Basics of Remote Sensing.

- Photogrammetry and Cartography.

- Geographical Information System and Global Navigation Satellite System.

- Digital Image Processing.

The registration and access to IIRS e-learning programme is free and open to all the users in Internet domain. The basis qualification for appearing in examination to get a certificate from IIRS is as following:

- Persons who have successfully completed graduation or 3 years diploma after 10th standard or equivalent are eligible.

or

- Working Professionals with $10+2$ educational qualification and minimum 5 years' experience in geo-spatial domain or related areas.

The participants can register through IIRS official website www.iir.gov.in or at e-learning website http://elearning.iirs.gov.in.

Although e-learning based training and education in India is in very early stage but the initial response to the IIRS e-learning programme is very encouraging. More than 1000 participants are participating in these programmes within one month of its release.

\section{CONCLUSION}

The e-reading based systems works on downloading the reading contents and read it offline while e-learning is a systematic learning system which guides the learners online with various learning methodologies implemented in LMS. E-learning based education and training is one of emerging mode of learning by harnessing the power of ICT and educational tools. The utilization of Internet and multimedia technology for capacity is very effective for remote sensing and geo-spatial technology. Various e-learning object standards are providing an interoperable solution for online learning contents. The role of open source/freeware Learning Management System (LMS) is very important for wider uses and application of this technology. Moodle LMS is one of the mature software product which provide excellent platform to run e-learning based online courses. The e-learning concept is very new in education system where sometimes the students are confused in e-reading and elearning. The validity of e-learning certificates and degree is still in discussion stage while for learners it is a successful platform. In geo-spatial domain e-learning based capacity building is good for theory and practical but the fields survey exercises are again depend on self-motivation of the participants. In future some virtual simulations for field exercises can be attempted for understanding the geographical features.

\section{ACKNOWLEDGEMENT}

Authors express their gratitude to Chairman, Indian Space Research Organisations (ISRO) for motivation and encouragements. Thanks to NNRMS for financial support. The contribution of different e-learning teams of IIRS, subject experts are duly acknowledged. Special thanks to Dr. Anil Kumar, Scientist IIRS and team for critical review of the elearning contents.

\section{REFERENCES}

Bates, A. and Poole, G. (2003), "Effective Teaching with Technology in Higher Education", San Francisco: JosseyBass/John Wiley, 2003

Clark, R. C., Mayer, R. E. (2007). eLearning and the Science of Instruction. San Francisco: Pfeiffer

Karnatak Harish C., Shukla Reedhi, Sharma Vinod, Murthy YVS and Bhanumurthy V (2012), "Spatial mashups technology and real time data integration in geo-web application using open source GIS- A case study for disaster management", Geocarto International ( ) Taylor \& Francis, Volume 27, Issue 6, pp-499-514, DOI: 10.1080/10106049.2011.650651.

Karnatak Harish Chandra, Saran Sameer, Bhatia Karamjit and Roy P.S., (2007), "Multicriteria Decision Analysis in Web GIS Environment", Geoinformatica, (2007) 11, pp: 407-429: Springer Science DOI 10.1007/s10707-006-0014-8.

Karon, R. L. (2000). Bankers go online: Illinois banking company learns benefits of e-training. E-learning, 1(1) 38-40.

Loutchko, Iouri, Kurbel, Karl, Pakhomov, Alexei (2002), "Production and Delivery of Multimedia Courses for Internet Based Virtual Education;", The World Congress "Networked Learning in a Global Environment: Challenges and Solutions for Virtual Education", Berlin, Germany, May 1 - 4, 2002

Mayer, Frederick (1960) "History of Educational Thought", Ohio: Charles E. Merril Book, Inc, 1960.

OECD (2005) "E-Learning in Tertiary Education: Where Do We Stand? “, Paris: OECD

PODCASTS IN EDUCATION: WHAT, WHY AND HOW?" Proceedings of the Academy of Educational Le adership, $\begin{array}{lllll}\text { Volume } & 14, & \text { Number } & 1 & ,\end{array}$ (http://web.archive.org/web/20130927071851/http: //www.appstate.edu/ koppenhaverd/rcoe/5532/rea $\mathrm{d} /$ podcast/robinson09.pdf) (Accessesd on 14th Novomber 2014)

SCORM (2014) - Project Tin Can: Phase 3 - Capabilities". SCORM - Project Tin Can: Phase 3-Capabilities (http://scorm.com/tincancapabilities/). Rustici Sofftware (last accesed 14th November, 2014)

Tavangarian D., Leypold M., Nölting K., Röser M.,(2004). Is elearning the Solution for Individual Learning? Journal of elearning, 2004. 
The International Archives of the Photogrammetry, Remote Sensing and Spatial Information Sciences, Volume XL-8, 2014 ISPRS Technical Commission VIII Symposium, 09 - 12 December 2014, Hyderabad, India

Trentin G. (2010), "Networked Collaborative Learning: social interaction and active learning", Woodhead/Chandos Publishing Limited, Cambridge, UK, ISBN 978-1-84334-501-5.

Wikkipedia- http://en.wikipedia.org/, (Last accessed 12th November 2014)

Zahm, S. (2000). No question about it - e-learning is here to stay: A quick history of the e-learning evolution. E-learning, 1 (1) $44-47$.

\section{$\underline{U R L S:}$}

http://www.creativity-portal.com, www.wannalearn.com,

http://www.howstuffworks.com/ 